\title{
In vivo antimutagenic activity of the medicinal plants Pfaffia glomerata (Brazilian ginseng) and Ginkgo biloba
}

\author{
I.V. Almeida ${ }^{1}$, E. Düsman ${ }^{2}$, G.I. Mattge ${ }^{1}$, F. Toledo ${ }^{1}$, A.F. Reusing ${ }^{1}$ and \\ V.E.P. Vicentini ${ }^{1}$ \\ ${ }^{1}$ Laboratório de Mutagênese e Monitoramento Ambiental, \\ Departmento de Biotecnologia, Genética e Biologia Celular, \\ Universidade Estadual de Maringá, Maringá, Paraná, Brasil. \\ ${ }^{2}$ Departamento Acadêmico de Química e Biologia, \\ Universidade Tecnológica Federal do Paraná, \\ Campus Francisco Beltrão, Brasil. \\ Corresponding author: I.V. Almeida \\ E-mail: igoralmeida.bio@gmail.com
}

Genet. Mol. Res. 16 (3): gmr16039785

Received July 28, 2017

Accepted August 29, 2017

Published September 27, 2017

DOI http://dx.doi.org/10.4238/gmr16039785

Copyright (C) 2017 The Authors. This is an open-access article distributed under the terms of the Creative Commons Attribution ShareAlike (CC BY-SA) 4.0 License.

\begin{abstract}
Complementary and alternative therapies, including the use of medicinal plants, have become almost standard among the world's population. Pfaffia glomerata (PG), popularly known as Brazilian ginseng, is widely used as a restorer of vital functions, increasing mental balance, and is used for the treatment of diabetes and rheumatism. Ginkgo biloba (GB) is one of the oldest known gymnosperms, whose leaves are widely used for its potentiating action on the nervous system. The biological activities of these plants were determined on bone marrow cells of Wistar rats treated in vivo. For cytotoxic and mutagenic acute analysis, plant extracts were administered by gavage at concentrations of $0.15,1.5$, and $15 \mathrm{mg} \mathrm{PG} / \mathrm{mL}$ water and 1,2 , and $3 \mathrm{mg} \mathrm{GB} / \mathrm{mL}$ water. For antimutagenic analysis, plant extracts aqueous solution $(\mathrm{PG}$,
\end{abstract}


$1.5 \mathrm{mg} / \mathrm{mL}$ or $\mathrm{GB}, 2 \mathrm{mg} / \mathrm{mL}$ ) were administered by gavage before (pretreatment), simultaneous to (simultaneous treatment), or after (post-treatment) the administration of cyclophosphamide $(1.5 \mathrm{mg} / \mathrm{mL}$, intraperitoneally). Both plant extracts have no cytotoxic or mutagenic potential, and they significantly reduce the percentage of chromosomal aberrations induced by the cyclophosphamide given simultaneously (PG, 87\%; GB, 75\%), pretreatment (PG, 98\%, GB, 78\%) and posttreatment (PG, 99\%, GB, 75\%). This beneficial antimutagenic property of the medicinal plants $P$. glomerata and G. biloba presented here, with no cytotoxic or mutagenic activity, can efficiently contribute to improvements in quality of life and recovery for people undergoing chemotherapeutic treatment, or those looking for health and preventive habits.

Key words: Alternative therapies; Chromosome aberration; Cytotoxicity; Herbal extract; Mutagenicity

\section{INTRODUCTION}

Plants have been used for medicinal purposes since the earliest historical registers. China, India, and Egypt were most likely the pioneers in the use of medicinal herbs, and phytotherapy was already widely practiced in Europe in Medieval times. Since then, a wide variety of plants has been used for medical treatments (Licata et al., 2013). In Brazil, folk medicine is derived from a mixture of Brazilian indigenous cultures as well as European and African influences from the period of colonization, forming the basis for the traditional use of medicinal plants (Santos et al., 2012b).

The Pfaffia genus occurs in Guyana, Bolivia, Argentina, and in Brazil, mainly in the States of São Paulo, Paraná, Mato Grosso do Sul, and Goiás. Pfaffia glomerata (Spreng.) Pedersen (Amaranthaceae) is a plant whose tuberous roots are widely used in Brazilian folk medicine; it is a perennial herb that is traditionally known as Brazilian ginseng due to its morphological and chemical similarity with Korean ginseng (Panax spp) (Festucci-Buselli et al., 2008; Santos et al., 2012a). The Brazilian ginseng is used for restoring vital functions, increasing physical strength and mental equilibrium, and protecting the gastric mucosa from injury. It is also used for the treatment of diabetes and rheumatism, and it possesses antioxidant, analgesic, anti-inflammatory, trypanocidal, antileishmanial, and aphrodisiac actions (De Oliveira, 1986; Neto et al., 2004; Queiroz et al., 2014).

Several important compounds have been isolated and identified from the roots of P. glomerata, such as pfaffic acid, some saponins named pfaffosides A-F, glomeric acid (a triterpenoid), and pfameric acid (a nortriterpenoid), together with ecdysterone ( $\beta$-ecdysone), rubrosterone, oleanolic acid, $\beta$-glucopyranosyl oleanolate, glycosides, and sterols (stigmasterol and sitosterol). Different studies have shown that these elements have antineoplastic activities. Saponins of different origins have been shown to have antineoplastic activities by reducing cellular proliferation, inducing apoptosis and increasing immunological response (Felipe et al., 2014). The ginsenosides (triterpene saponins) are the main active components responsible for the multiple effects of Korean and Brazilian ginseng. The older the plant, the higher the total amount of ginsenosides in roots (Radad et al., 2011).

Genetics and Molecular Research 16 (3): gmr16039785 
Ginkgo biloba L. is considered a "living fossil" because it is the oldest gymnosperm, able to exceed 1000 years of life. It is the only representative of Ginkgoaceae family, originally from China, Japan, and Korea (Jacobs and Browner, 2000). The leaves, fruits, and seeds of $G$. biloba are widely used in popular medicine for the treatment of a variety of diseases, including Alzheimer's disease, dementia, low cerebral and ocular blood flow, hypertension, fatigue, anxiety, depression, and premenstrual discomfort. In addition to its anticoagulant activity, $G$. biloba is also a modulator of apoptosis and is an antioxidant (Qiao et al., 2014). In recent decades, G. biloba has become important for horticulture as it is widely cultivated around the world due to its tolerance to heat and cold, desiccation and salinity, as well as being very resistant to diseases (Wang et al., 2013).

Various chemical constituents of G. biloba have been isolated and identified in several publications, including organic and inorganic compounds, simple carbohydrates, organic acids, and secondary metabolites, such as terpene trilactones (ginkgolide and bilobalide) and flavonoids (ginkgoflavonoids). Terpene trilactones and flavonoids, together, are considered the constituents with the greatest bioactive potential from this plant (Sabater-Jara et al., 2013). The standardized G. biloba EGb761 extract (which is among the most studied and best-selling herbal medications worldwide) is obtained from dried leaves and contains $6 \%$ terpene trilactones (3.1\% ginkgolide and $2.9 \%$ bilobalide) and $24 \%$ flavonoids (van Beek and Montoro, 2009).

The world's population is increasing the use of natural products to have a better quality of life or is using them as an adjuvant therapy to conventional treatments, mainly by consumption of dehydrated vegetable pieces, pills, infusions (tea), extracts, or other preparations. Therefore, the aim of this study was to evaluate the cytotoxic, mutagenic, and antimutagenic/protective potential of two commercial presentations of the medicinal plants $P$. glomerata and G. biloba, which are recognized as revitalizing and improvers of brain capacity in humans, against the mutagenic/clastogenic/pro-oxidant actions of the chemotherapeutic agent cyclophosphamide in bone marrow cells of Wistar rats in vivo.

\section{MATERIAL AND METHODS}

\section{Treatment solutions}

Commercial formulations of the two medicinal plants were acquired from Herbarium ${ }^{\circledR}$ Laboratory (Curitiba - Brazil). According to the manufacturer, Ginseng Brasileiro ${ }^{\circledR}$ is presented in the form of capsules containing $300 \mathrm{mg}$ P. glomerata (PG) root dry extract, with the standardized extract containing $0.96 \% \beta$-ecdysone $(2.88 \mathrm{mg})$. The content of the capsule was diluted in water at concentrations of $0.15,1.5$, and $15 \mathrm{mg} / \mathrm{mL}$. G. biloba ${ }^{\circledR}$ is presented in the form of capsules containing $20 \mathrm{mg} \mathrm{G}$. biloba (GB) leaves dry extract and starch as the excipient. According to the manufacturer, the extract is standardized to $24 \%$ ginkgoflavonoids $(4.8 \mathrm{mg})$ and $6 \%$ terpene lactones $(1.2 \mathrm{mg})$. The content of the capsule was diluted in water at concentrations of 1,2 , and $3 \mathrm{mg} / \mathrm{mL}$. The concentrations were obtained by extrapolating the use and body weight of the human to rats and ten times higher and lower.

\section{Wistar rats}

Six Wistar rats (Rattus norvegicus), three males and three females for each group were

Genetics and Molecular Research 16 (3): gmr16039785 
obtained from the Central Vivarium of the State University of Maringá. Experiments were carried out using 35-day-old rats weighing approximately $100 \mathrm{~g}$ body weight (bw).

\section{Treatments}

For cytotoxic and mutagenic acute analysis, plant extracts were administered by gavage $(1 \mathrm{~mL} / 100 \mathrm{~g} \mathrm{bw})$. For mutagenic analysis, plant extract aqueous solutions (PG: 0.15, 1.5 , and $15 \mathrm{mg} / \mathrm{mL}$ or GB: 1,2 , and $3 \mathrm{mg} / \mathrm{mL})$ were administered by gavage $(1 \mathrm{~mL} / 100 \mathrm{~g} \mathrm{bw})$. For antimutagenic analysis, plant extract aqueous solutions (PG $1.5 \mathrm{mg} / \mathrm{mL}$ or GB $2 \mathrm{mg} / \mathrm{mL}$ ) were administered by gavage $(1 \mathrm{~mL} / 100 \mathrm{~g} \mathrm{bw})$ prior ( $2 \mathrm{~h}$ pretreatment - PRE), simultaneous to (simultaneous treatment - SIM), or after ( $2 \mathrm{~h}$ post-treatment - POST) the application of an intraperitoneal injection of $1.5 \mathrm{mg} / \mathrm{mL}$ cyclophosphamide $(\mathrm{CP})$. The control group $(\mathrm{CO})$ was administered water by gavage $(1 \mathrm{~mL} / 100 \mathrm{~g} \mathrm{bw})$ and the $\mathrm{CP}$ group (positive group) received an intraperitoneal injection of the drug $(1.5 \mathrm{mg} / \mathrm{mL} 100 \mathrm{~g} \mathrm{bw})$. The animals were euthanized $24 \mathrm{~h}$ after the treatments with an intraperitoneal dose of $0.5 \mathrm{~mL}$ Thionembutal ( 1 g sodium thiopental $/ 25 \mathrm{~mL}$ distilled water).

\section{Chromosomal aberration test}

The chromosomal aberration test was performed on bone marrow cells of Wistar rats using the Ford and Hamerton (1956) method, with some modifications. Mitotic cells were interrupted in metaphase with the intraperitoneal administration of $0.5 \mathrm{~mL} / 100 \mathrm{~g}$ bw colchicine $(0.16 \%), 90 \mathrm{~min}$ before euthanasia.

Analysis of the slides was performed by a light microscope, analyzing 100 metaphases per animal, totaling 600 cells each for control and treatment groups. Cells were assessed for the appearance of alterations, such as gaps, breaks, fragments, and others.

Mitotic index (MI) for the cytotoxicity evaluation was calculated from 5000 cells from each sex, totaling 10000 cells per group. The MI was calculated as a percentage as follows: the number of proliferating cells divided by the total number of cells present in the fields.

\section{Ethics statement}

During the experimentation period, the animals remained under controlled temperatures of $\pm 25^{\circ} \mathrm{C}$, with humidity at $\pm 50 \%$ and with a photoperiod of a 12 -h light/dark cycle. Furthermore, all ethical principles, protocols, and regulations on experimentation with laboratory animals were used according to the standards established internationally and by the approved project by the Ethics Committee on Animal Use in Experimentation/State University of Maringá, following the Ethical Principles for Animal Experimentation established by the Brazilian College of Animal Experimentation (COBEA), as well as the specific treatment and collection protocols made to chromosomal aberration test.

\section{Statistical analyses}

Statistical analyses was performed using the chi-square test $\left(\chi^{2}\right)(\mathrm{N}=6, \alpha=0.05)$.

Genetics and Molecular Research 16 (3): gmr16039785 


\section{RESULTS AND DISCUSSION}

A large and growing use of medicinal plants and their extracts, especially P. glomerata and G. biloba, for the treatment of various diseases and the search for improved quality of life directed the present study to investigate the cytotoxicity of aqueous solutions of these plants on Wistar rats' bone marrow cells in vivo. The results indicate that the mutagenicity test of Brazilian ginseng showed no cytotoxic effects at any of the tested concentrations when compared to the control, as measured by the MI (PG: $[0.15] \chi^{2}=0.07 ;[1.5] \chi^{2}=0.16 ;[15] \chi^{2}$ $=0.01)$. The same effect was observed for treatment with G. biloba $\left(\mathrm{GB}:[1] \chi^{2}=0.01 ;[2] \chi^{2}=\right.$ $0.01 ;[3] \chi^{2}=0.09$ ) (Table 1 ). With respect to the cytotoxicity analyses in the antimutagenicity test, no changes in the MI for treatment with different concentrations of the two plants were observed compared to the control $\left(\mathrm{CP} \chi^{2}=0.08\right.$; PG [1.5] $\chi^{2}=0.06$; PG: $\operatorname{SIM} \chi^{2}=0.22$, PRE $\chi^{2}=0.25$, POST $\chi^{2}=0.19$; GB [2] $\chi^{2}=0.004$; GB: SIM $\chi^{2}=0.09$, PRE $\chi^{2}=0.29$, POST $\chi^{2}=$ 0.13 ) (Table 1).

\begin{tabular}{|c|c|c|c|c|}
\hline \multirow[t]{2}{*}{ Treatments } & \multicolumn{2}{|c|}{ Pfaffia glomerata } & \multicolumn{2}{|c|}{ Ginkgo biloba } \\
\hline & Groups & $\mathrm{MI}(\%) \pm \mathrm{SD}$ & Groups & $\mathrm{MI}(\%) \pm \mathrm{SD}$ \\
\hline \multirow{5}{*}{ Mutagenicity } & $\mathrm{CO}$ & $1.43 \pm 0.17$ & $\mathrm{CO}$ & $1.43 \pm 0.17$ \\
\hline & $\mathrm{CP}$ & $1.13 \pm 0.13$ & $\mathrm{CP}$ & $1.13 \pm 0.13$ \\
\hline & PG [0.15] & $1.11 \pm 0.14$ & $\mathrm{~GB}[1]$ & $1.56 \pm 0.19$ \\
\hline & PG [1.5] & $1.92 \pm 0.23$ & $\mathrm{~GB}[2]$ & $1.33 \pm 0.16$ \\
\hline & PG [15] & $1.29 \pm 0.15$ & GB [3] & $1.08 \pm 0.13$ \\
\hline \multirow{6}{*}{ Antimutagenicity } & $\mathrm{CO}$ & $1.41 \pm 0.17$ & $\mathrm{CO}$ & $1.41 \pm 0.19$ \\
\hline & $\mathrm{CP}$ & $1.08 \pm 0.13$ & $\mathrm{CP}$ & $1.08 \pm 0.13$ \\
\hline & PG [1.5] & $1.12 \pm 0.14$ & GB [2] & $1.33 \pm 0.16$ \\
\hline & PG SIM & $0.85 \pm 0.10$ & GB SIM & $1.06 \pm 0.13$ \\
\hline & PG PRE & $0.82 \pm 0.12$ & GB PRE & $0.77 \pm 0.09$ \\
\hline & PG POST & $0.89 \pm 0.11$ & GB POST & $0.99 \pm 0.12$ \\
\hline
\end{tabular}

Mutagenicity test - CO: control group (1 mL water/100 g bw); CP: cyclophosphamide $1.5 \mathrm{mg} / \mathrm{mL}$; PG: $0.15,1.5$, or $15 \mathrm{mg} / \mathrm{mL}$ per $100 \mathrm{~g}$ bw; GB: 1,2 , or $3 \mathrm{mg} / \mathrm{mL}$ per $100 \mathrm{~g}$ bw. Antimutagenicity test - CO: control group $(1 \mathrm{~mL}$ water/100 g bw); CP: cyclophosphamide $1.5 \mathrm{mg} / \mathrm{mL}$; PG: $1.5 \mathrm{mg} / \mathrm{mL}$ per $100 \mathrm{~g}$ bw; GB: $2 \mathrm{mg} / \mathrm{mL}$ per $100 \mathrm{~g}$ bw; treatments: simultaneous (SIM), pretreatment (PRE), and post-treatment (POST) to cyclophosphamide.

Studies with P. glomerata are scarce in the literature. However, studies with Pfaffia paniculata, which is morphologically and chemically similar to Brazilian ginseng, have revealed that this plant possesses chemotherapeutic effects, reducing cell proliferation and increasing the rate of apoptosis in induced hepatocellular carcinoma in BALB/c mice, indicating a cytotoxic effect of the root (Silva et al., 2010). Nagamine et al. (2009) also observed cytotoxic effects of butanolic extract from P. paniculata in human breast carcinoma (MCF-7) cells and demonstrated the degradation of cytoplasmic components, the disappearance of mitochondria, rupture of the plasma membrane, and profound changes in the nuclear morphology. In this study, it is noteworthy that normal bone marrow cells were evaluated, which may explain the absence of cytotoxic effects of Brazilian ginseng extract, which is different from what was found in studies with tumor cells. Besides, the treatments in our study were performed in vivo and not in vitro.

Regarding the cytotoxic activity of G. biloba, Hecker et al. (2002) corroborate these results and found no cytotoxic effects for EGb761 in human keratinocytes (HaCaT) and epithelial cells from monkey kidney (LLC-MK 2 ). The authors also identified substances with

Genetics and Molecular Research 16 (3): gmr16039785 
high cytotoxic potential that were derived from a ginkgolic acid (alkylphenols). However, these substances appear in concentrations up to $5 \mathrm{ppm}$ in commercial extracts, which, according to the authors, would be insufficient to promote cytotoxicity.

In the mutagenicity test, we evaluated the potential of the Brazilian ginseng and $G$. biloba solutions to induce chromosomal aberrations. Additionally, in the antimutagenicity test, we evaluated the antimutagenic and protective or reductive activity of the cyclophosphamideinduced clastogenicity in the bone marrow cells of Wistar rats. The major chromosomal abnormalities found in the analysis of metaphase were chromatic (cb) or isochromatic (ib) breaks, chromatic (cg) or isochromatic (ig) gaps, acentric fragments (af), minutes (mn), and double minutes $(\mathrm{dm})$.

Despite the lack of cytotoxicity in this study, the chemotherapeutic drug cyclophosphamide, which is highly clastogenic and pro-oxidant (Colvin, 1999), was effective in inducing chromosomal damage in the mutagenicity and antimutagenicity tests (Figure 1) when compared to control (CP: $\chi^{2}=499.60$ and 1336.36, respectively). The aberrations observed in this treatment were $6 \mathrm{cg}+46 \mathrm{cb}+27$ af for mutagenicity, and $29 \mathrm{cg}+4 \mathrm{ig}+16 \mathrm{cb}$ $+14 \mathrm{ib}+20 \mathrm{af}+30 \mathrm{mn}+15 \mathrm{dm}$ for antimutagenicity tests.

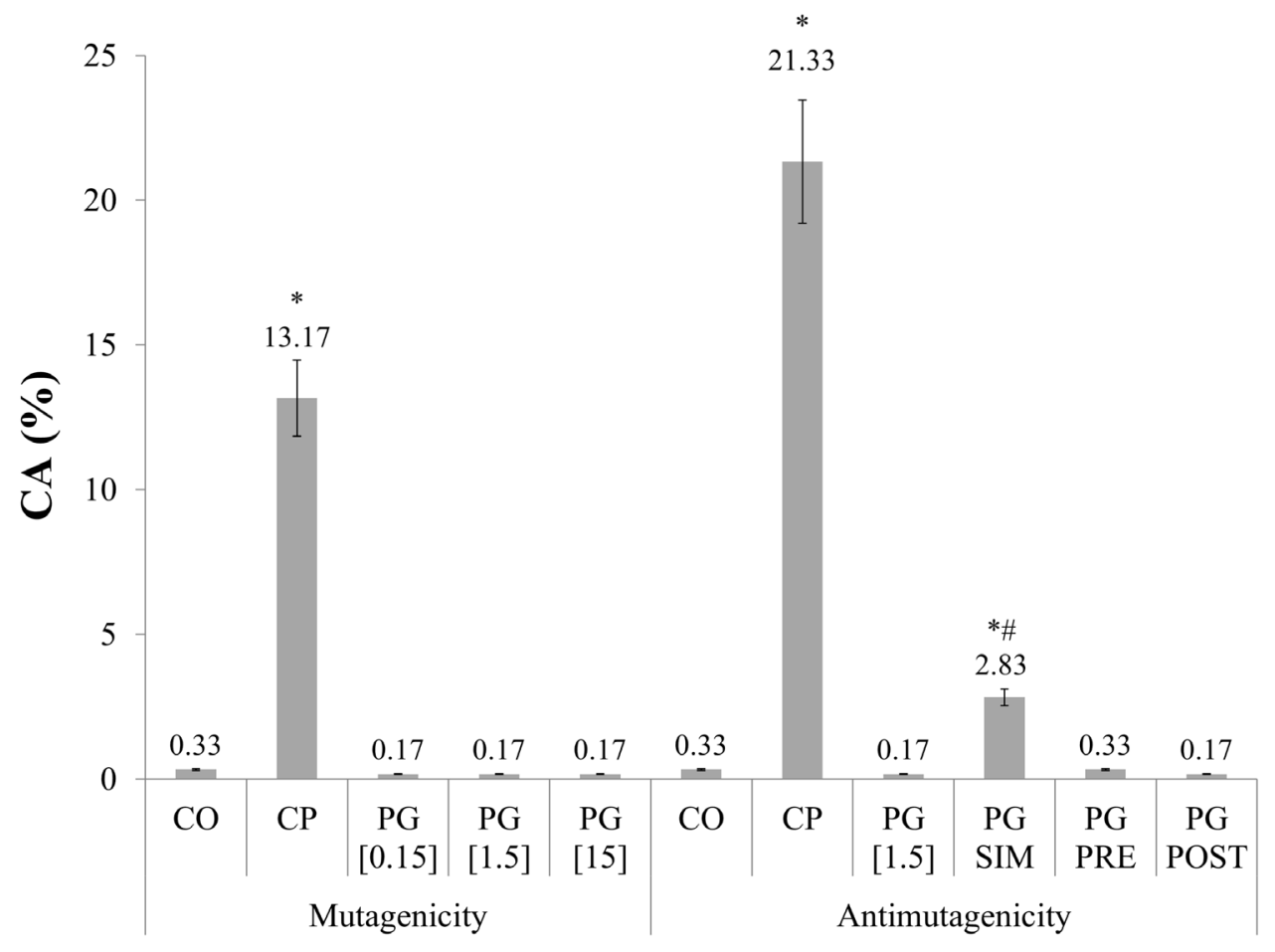

Figure 1. Chromosomal aberration (CA) (mean percentage and standard deviation) for the mutagenicity and antimutagenicity tests with Pfaffia glomerata (PG) aqueous solutions in bone marrow cells of Wistar rats. Mutagenicity test - CO: control group (1 mL water/100 g bw); CP: cyclophosphamide $1.5 \mathrm{mg} / \mathrm{mL}$; PG: $0.15,1.5$, or $15 \mathrm{mg} / \mathrm{mL}$ per $100 \mathrm{~g}$ bw. Antimutagenicity test - CO: control group ( $1 \mathrm{~mL}$ water/100 g bw); CP: cyclophosphamide $1.5 \mathrm{mg} / \mathrm{mL}$; PG: $1.5 \mathrm{mg} / \mathrm{mL}$ per $100 \mathrm{~g}$ bw, in simultaneous treatment (SIM), pretreatment (PRE), and post-treatment (POST) cyclophosphamide. * Results were statistically significant compared to CO. ${ }^{\text {"Results were statistically }}$ significant compared to $\mathrm{CP}$.

Genetics and Molecular Research 16 (3): gmr16039785 
Figure 1 shows the percentage of chromosomal aberrations found in animals treated with the three concentrations of Brazilian ginseng, which showed no mutagenic potential and was statistically similar to the control (PG: [0.15] $\chi^{2}=0.08 ;[1.5] \chi^{2}=0.08 ;[15] \chi^{2}=$ 0.08 ; damage was represented, respectively, by $1 \mathrm{cg}, 1 \mathrm{cb}$, and $1 \mathrm{cg}$ ). In the antimutagenicity test, the results show that the plant extract significantly reduced the percentage of damage induced by cyclophosphamide (PG: SIM $\chi^{2}=16.04$; PRE $\chi^{2}=20.67$; POST $\chi^{2}=20.99$ ). Cyclophosphamide-induced damage was reduced by $87 \%$ for simultaneous treatment, $98 \%$ for pretreatment, and $99 \%$ for post-treatment with PG. However, only the simultaneous treatment was not statistically equivalent to the control (PG: SIM $\chi^{2}=18.94$; PRE $\chi^{2}=0.09$; POST $\chi^{2}$ $=0.08)$. The chromosomal aberrations that were found using PG treatment were $12 \mathrm{cb}+5 \mathrm{cg}$ (SIM), $2 \mathrm{cb}$ (PRE), and $1 \mathrm{cb}$ (POST).

The present study demonstrates, for the first time, that Brazilian ginseng aqueous solution lacks mutagenic effects and exhibits antimutagenic potential. The combined effect of its components may have been responsible for the protective action of the medicinal plant against cyclophosphamide-induced chromosomal damage in the bone marrow cells of Wistar rats in vivo. Studies performed with substances isolated from this plant strengthen the protective effect reported here. Nakai et al. (1984) isolated pfaffic acids and pfaffosides and verified their inhibitory activity on the proliferation of melanoma cell lines in vitro. Villaseñor et al. (2002) did not observe mutagenic activity and found an antimutagenic effect of sitosterol, observing a significant reduction $(61.7 \%)$ in the number of micronuclei induced by tetracycline in mouse polychromatic erythrocytes. Furthermore, Wangari-Talbot et al. (2012) studied the effects of ecdysone, an important component of the Brazilian ginseng root, and elucidated the mechanism of RNA interference that inhibits membrane receptors related to the proliferation of human melanoma cells in vivo and in vitro, showing great therapeutic potential for this disease.

Figure 2 shows the percentage of chromosomal abnormalities found for the treatment with the aqueous solution of $G$. biloba, which, at the three concentrations tested, also showed no mutagenic potential and was statistically similar to the control (GB: [1] $\chi^{2}=0.07 ;[2] \chi^{2}$ $=0.07 ;$ [3] $\chi^{2}=0.08$; GB [3] damage was represented by $1 \mathrm{cg}$ and GB [1] and [2] showed no alterations. Therefore, a single damage event was attributed to statistical calculations). In the antimutagenicity test, the results showed that the plant significantly reduced the percentage of cyclophosphamide-induced damage (GB: SIM $\chi^{2}=12.00$; PRE $\chi^{2}=13.01$; POST $\chi^{2}=$ 12.00). The decrease in the alterations caused by cyclophosphamide for $G$. biloba was $75 \%$ for simultaneous and post-treatment and $78 \%$ for the pretreatment. However, this reduction was not statistically equivalent compared to control (GB: SIM $\chi^{2}=75.76$; PRE $\chi^{2}=57.08$; POST $\left.\chi^{2}=75.76\right)$. The alterations found in GB treatment were: $6 \mathrm{cg}+3 \mathrm{ig}+10 \mathrm{cb}+5 \mathrm{ib}+1 \mathrm{af}+5$ $\mathrm{mn}+2 \mathrm{dm}(\mathrm{SIM}), 4 \mathrm{cg}+3 \mathrm{ig}+10 \mathrm{cb}+4 \mathrm{ib}+1 \mathrm{af}+5 \mathrm{mn}+1 \mathrm{dm}$ (PRE), and $7 \mathrm{cg}+3 \mathrm{ig}+7$ $\mathrm{cb}+1 \mathrm{ib}+6 \mathrm{af}+8 \mathrm{mn}(\mathrm{POST})$.

The time of exposure to a particular agent can be crucial for the occurrence of adverse effects and have even more serious consequences for the health of the individual. In contrast to the results presented here with acute G. biloba treatment, the National Toxicology Program (NTP) presented an extensive study performed with mice and rats chronically treated with commercial G. biloba extracts for 3 months or 2 years. It was found that a significant number of animals developed several types of cancer involving organs such as the thyroid, liver, bone marrow, and respiratory system, and severe nephropathology (NTP - National Toxicology Program, 2013). Lin et al. (2014) also found evidence of carcinogenesis in rodents

Genetics and Molecular Research 16 (3): gmr16039785 
induced by commercial G. biloba extracts. However, the authors suggest that further studies should be developed, primarily to ensure the quality of these products that are extensively commercialized around the world.

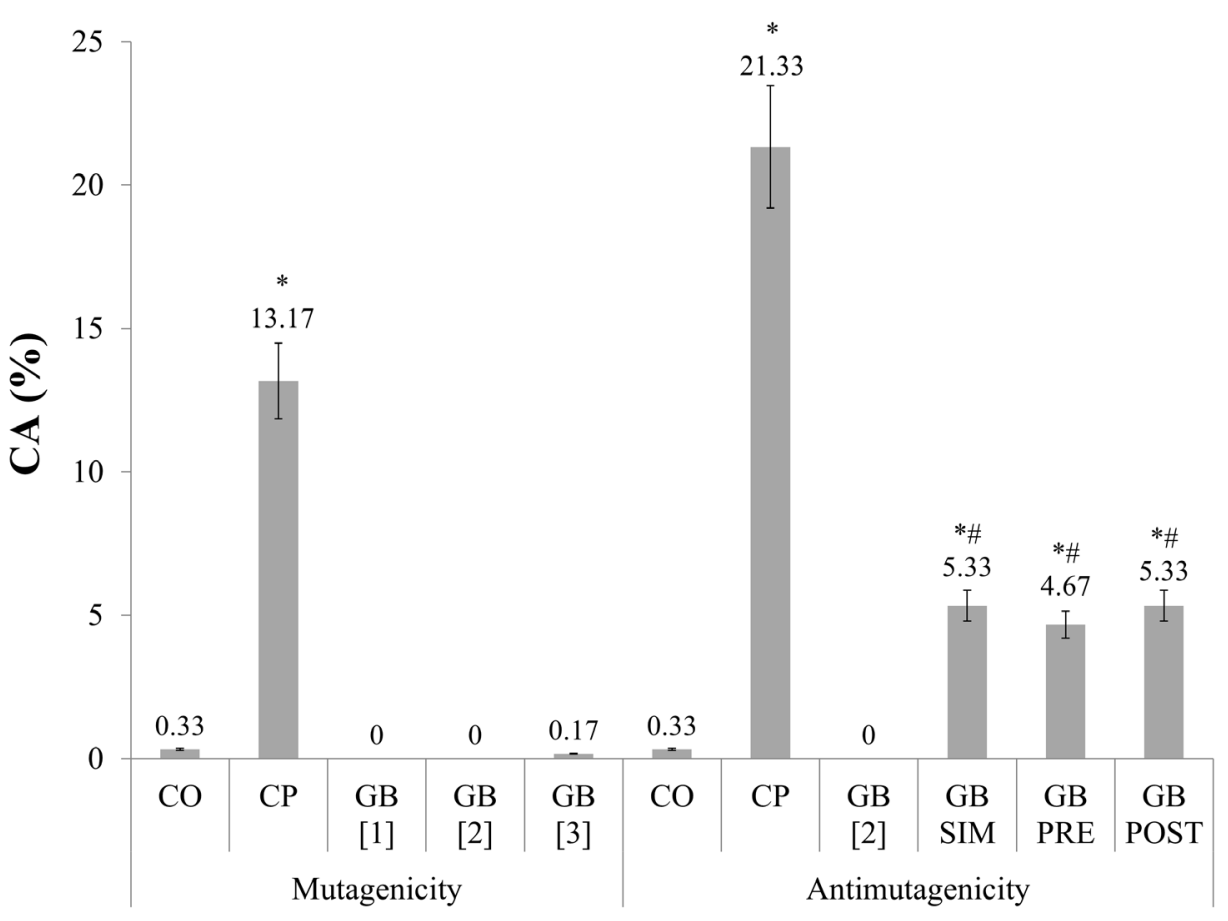

Figure 2. Chromosomal aberration (CA), reported as a mean percentage and standard deviation, for the mutagenicity and antimutagenicity tests with Ginkgo biloba (GB) aqueous solutions in Wistar rats' bone marrow cells. Mutagenicity test: CO: control group ( $1 \mathrm{~mL}$ water/100 g bw); CP: cyclophosphamide $1.5 \mathrm{mg} / \mathrm{mL}$; GB: 1,2 , or $3 \mathrm{mg} / \mathrm{mL}$ per $100 \mathrm{~g}$ bw. Antimutagenicity test: CO: control group ( $1 \mathrm{~mL}$ water $/ 100 \mathrm{~g} \mathrm{bw})$; CP: cyclophosphamide $1.5 \mathrm{mg} / \mathrm{mL}$; GB: $2 \mathrm{mg} / \mathrm{mL}$ per $100 \mathrm{~g} \mathrm{bw}$ ), in simultaneous treatment (SIM), pretreatment (PRE), and post-treatment (POST) to cyclophosphamide. *Results were statistically significant compared to CO. "Results were statistically significant compared to $\mathrm{CP}$.

Despite the findings of adverse effects, other studies show beneficial effects from the use of G. biloba extracts, which corroborate the antimutagenic effects presented in this paper. The anticlastogenic effect of the EGb761 extract was verified by the micronucleus test in patients with hyperthyroidism that underwent radiation therapy with iodine-131. It was found that supplementation reduces the genotoxic damage induced by radiation, without compromising the clinical recovery of the patients (Dardano et al., 2007). Sener et al. (2006) analyzed the same radioprotective effect in which the G. biloba extract reduced the oxidative damage induced by ionizing radiation and the level of DNA fragmentation in the ileum of rats supplemented for 15 days before exposure to radiation.

The antimutagenic activity of the EGb761 extract was also evaluated in the photosynthetic flagellate Euglena gracilis (Krizková et al., 2008). In this test, the extract was capable of efficiently adsorbing the acridine orange molecule, which is responsible for inducing DNA damage in chloroplasts. This adsorption capacity occurred primarily through the carbohydrates

Genetics and Molecular Research 16 (3): gmr16039785 
present in the extract, which can also be present in the aqueous solution of the plant and have aided in reducing the cyclophosphamide-induced mutagenicity observed in this study.

Based on the mechanism of action for the chemotherapeutic drug, it is possible that the protective effects observed in the antimutagenicity test were caused by the antioxidant activity of the components of the analyzed medicinal plants, mainly pfaffic acids and ginkgoflavonoids, which have the ability to capture the reactive oxygen species produced by cyclophosphamide. Moreover, these results corroborate those of Zhang et al. (2008), who used cyclophosphamide as the damaging agent and identified antigenotoxic and antiapoptotic effects of saponins isolated from Panax ginseng (also present in P. glomerata) in mouse bone marrow cells and peripheral blood lymphocytes using the comet assay. According to the authors, they also observed the increased activity of antioxidant enzymes that are normally inhibited in the presence of cyclophosphamide.

In the present study, the antimutagenic effects of aqueous solutions from both medicinal plant extracts and their phytocomplexes were evident. However, the protective actions on the DNA exerted by the Brazilian ginseng were higher than those observed for G. biloba, particularly when administered before (PRE) or following (POST) the application of cyclophosphamide, presenting results similar to the control. According to the mechanism of action, plant components can protect the sites in DNA that would be affected by the agent, inhibit the metabolic activation of pro-mutagens or scavenge reactive molecules in simultaneous and pretreatment. During post-treatment, the antimutagenic substance acts upon the process that induces the formation of mutations or on the mechanisms that repair DNA damage (Kada et al., 1978; Kuroda et al., 1992). The analysis of these results showed that both mechanisms of action might have contributed to the effective antimutagenic activity of Brazilian ginseng and G. biloba.

\section{CONCLUSIONS}

The results presented here at the chromosomal and cytological levels in the mammalian in vivo model, Rattus norvegicus, which has a metabolism similar to that of humans, indicate that the aqueous solutions of the dried extracts of medicinal plants, Pfaffia glomerata and Ginkgo biloba, do not present cytotoxic or mutagenic activity. These extracts are popular worldwide for increasing cognitive, stimulant, and antioxidant capacity in humans. Most importantly, the results showed that these two plants have an effective antimutagenic/ protective action, significantly reducing the DNA damage induced by the chemotherapeutic drug cyclophosphamide. This beneficial property of the medicinal plants presented here can efficiently contribute to improving the quality of life and the recovery of people undergoing chemotherapeutic treatment, or assist those looking for health and preventive habits.

\section{Conflicts of interest}

The authors declare no conflict of interest.

\section{ACKNOWLEDGMENTS}

We thank the research group of the Laboratory of Mutagenesis and Environmental Monitoring, State University of Maringá, and the National Council for Scientific and Technological Development (CNPq).

Genetics and Molecular Research 16 (3): gmr16039785 


\section{REFERENCES}

Colvin OM (1999). An overview of cyclophosphamide development and clinical applications. Curr. Pharm. Des. 5: 555-560.

Dardano A, Ballardin M, Ferdeghini M, Lazzeri E, et al. (2007). Anticlastogenic effect of Ginkgo biloba extract in Graves' disease patients receiving radioiodine therapy. J. Clin. Endocrinol. Metab. 92: 4286-4289. https://doi.org/10.1210/ jc. 2007-0597

De Oliveira F (1986). Pfaffia glomerata (Martius) Kuntze - the Brasilian ginseng. Rev. Bras. Farmacogn. 1: 86-92. https:// doi.org/10.1590/S0102-695X1986000100010

Felipe DF, Brambilla LZS, Porto C, Pilau EJ, et al. (2014). Phytochemical analysis of Pfaffia glomerata inflorescences by LC-ESI-MS/MS. Molecules 19: 15720-15734. https://doi.org/10.3390/molecules191015720

Festucci-Buselli RA, Contim LAS, Barbosa LCA, Stuart JJ, et al. (2008). Biosynthesis and potential functions of the ecdysteroid 20-hydroxyecdysone - A review. Botany 86: 978-987. https://doi.org/10.1139/B08-049

Ford CE and Hamerton JL (1956). A colchicine, hypotonic citrate, squash sequence for mammalian chromosomes. Stain Technol. 31: 247-251. https://doi.org/10.3109/10520295609113814

Hecker H, Johannisson R, Koch E and Siegers CP (2002). In vitro evaluation of the cytotoxic potential of alkylphenols from Ginkgo biloba L. Toxicology 177: 167-177. https://doi.org/10.1016/S0300-483X(02)00189-0

Jacobs BP and Browner WS (2000). Ginkgo biloba: a living fossil. Am. J. Med. 108: 341-342. https://doi.org/10.1016/ $\underline{\mathrm{S} 0002-9343(00) 00290-4}$

Kada T, Morita K and Inoue T (1978). Anti-mutagenic action of vegetable factor(s) on the mutagenic principle of tryptophan pyrolysate. Mutat. Res. 53: 351-353. https://doi.org/10.1016/0165-1161(78)90008-0

Krizková L, Chovanová Z, Duracková Z and Krajcovic J (2008). Antimutagenic in vitro activity of plant polyphenols: Pycnogenol and Ginkgo biloba extract (EGb 761). Phytother. Res. 22: 384-388. https://doi.org/10.1002/ptr.2331

Kuroda Y, Jain AK, Tezuka H and Kada T (1992). Antimutagenicity in cultured mammalian cells. Mutat. Res. 267: 201209. https://doi.org/10.1016/0027-5107(92)90064-9

Licata A, Macaluso FS and Craxì A (2013). Herbal hepatotoxicity: a hidden epidemic. Intern. Emerg. Med. 8: 13-22. https://doi.org/10.1007/s11739-012-0777-x

Lin H, Guo X, Zhang S, Dial SL, et al. (2014). Mechanistic evaluation of Ginkgo biloba leaf extract-induced genotoxicity in L5178Y cells. Toxicol. Sci. 139: 338-349. https://doi.org/10.1093/toxsci/kfu037

Nagamine MK, da Silva TC, Matsuzaki P, Pinello KC, et al. (2009). Cytotoxic effects of butanolic extract from Pfaffia paniculata (Brazilian ginseng) on cultured human breast cancer cell line MCF-7. Exp. Toxicol. Pathol. 61: 75-82. https://doi.org/10.1016/j.etp.2008.01.017

Nakai S, Takagi N, Miichi H, Hayashi S, et al. (1984). Pfaffosides, nortriterpenoid saponins, from Pfaffia paniculata. Phytochemistry 23: 1703-1705. https://doi.org/10.1016/S0031-9422(00)83473-1

Neto AG, da Silva Filho AA, Costa JMLC, Vinholis AHC, et al. (2004). Evaluation of the trypanocidal and leishmanicidal in vitro activity of the crude hydroalcoholic extract of Pfaffia glomerata (Amarathanceae) roots. Phytomedicine 11: 662-665. https://doi.org/10.1016/j.phymed.2003.06.005

NTP - National Toxicology Program. (2013). NTP technical report on the toxicology and carcinogenesis studies of Ginkgo biloba extract (CAS No. 90045-36-6) in F344/N rats and B6C3F1/N mice (gavage studies). NIH Publication No. 13-5920, March.

Qiao ZY, Huang JH, Ma JW, Xu YW, et al. (2014). Ginkgo biloba extract reducing myocardium cells apoptosis by regulating apoptotic related proteins expression in myocardium tissues. Mol. Biol. Rep. 41: 347-353. https://doi. org $/ 10.1007 / \mathrm{s} 11033-013-2868-9$

Queiroz AC, Dias TdeL, Da Matta CB, Cavalcante Silva LH, et al. (2014). Antileishmanial activity of medicinal plants used in endemic areas in northeastern Brazil. Evid. Based Complement. Alternat. Med. 2014: 478290. https://doi. org $/ 10.1155 / 2014 / 478290$

Radad K, Moldzio R and Rausch WD (2011). Ginsenosides and their CNS targets. CNS Neurosci. Ther. 17: 761-768. https://doi.org/10.1111/j.1755-5949.2010.00208.x

Sabater-Jara AB, Souliman-Youssef S, Novo-Uzal E, Almagro L, et al. (2013). Biotechnological approaches to enhance the biosynthesis of ginkgolides and bilobalide in Ginkgo biloba. Phytochem. Rev. 12: 191-205. https://doi.org/10.1007/ s11101-013-9275-7

Santos DT, Albarellib JQ and Meireles MAA (2012a). Simulation of an integrated sustainable production of extract from Brazilian ginseng roots with a cogeneration plant. Chem. Eng. Trans 29: 91-96.

Santos FJB, Moura DJ, Péres VF, Sperotto ARM, et al. (2012b). Genotoxic and mutagenic properties of Bauhinia platypetala extract, a traditional Brazilian medicinal plant. J. Ethnopharmacol. 144: 474-482. https://doi. org/10.1016/j.jep.2012.08.047

Genetics and Molecular Research 16 (3): gmr16039785 
Sener G, Kabasakal L, Atasoy BM, Erzik C, et al. (2006). Ginkgo biloba extract protects against ionizing radiationinduced oxidative organ damage in rats. Pharmacol. Res. 53: 241-252. https://doi.org/10.1016/j.phrs.2005.11.006

Silva TC, Cogliati B, da Silva AP, Fukumasu H, et al. (2010). Pfaffia paniculata (Brazilian ginseng) roots decrease proliferation and increase apoptosis but do not affect cell communication in murine hepatocarcinogenesis. Exp. Toxicol. Pathol. 62: 145-155. https://doi.org/10.1016/j.etp.2009.03.003

van Beek TA and Montoro P (2009). Chemical analysis and quality control of Ginkgo biloba leaves, extracts, and phytopharmaceuticals. J. Chromatogr. A 1216: 2002-2032. https://doi.org/10.1016/j.chroma.2009.01.013

Villaseñor IM, Angelada J, Canlas AP and Echegoyen D (2002). Bioactivity studies on $\beta$-sitosterol and its glucoside. Phytother. Res. 16: 417-421. https://doi.org/10.1002/ptr.910

Wang H, Cao F, Zhang W, Wang G, et al. (2013). Cloning and expression of stearoyl-ACP desaturase and two oleate desaturases genes from Ginkgo biloba L. Plant Mol. Biol. Report. 31: 633-648. https://doi.org/10.1007/s11105-012-0525-4

Wangari-Talbot J, Wall BA, Goydos JS and Chen S (2012). Functional effects of GRM1 suppression in human melanoma cells. Mol. Cancer Res. 10: 1440-1450. https://doi.org/10.1158/1541-7786.MCR-12-0158

Zhang QH, Wu CF, Duan L and Yang JY (2008). Protective effects of total saponins from stem and leaf of Panax ginseng against cyclophosphamide-induced genotoxicity and apoptosis in mouse bone marrow cells and peripheral lymphocyte cells. Food Chem. Toxicol. 46: 293-302. https://doi.org/10.1016/j.fct.2007.08.025

Genetics and Molecular Research 16 (3): gmr16039785 